\title{
CHANGES IN THE VASOMOTOR REACTION ASSOCIATED WITH GLOMUS TUMORS
}

\author{
By SAMUEL J. STABINS, JOHN J. THORNTON ANd W. J. MERLE SCOTT \\ (From the Department of Surgery, The University of Rochester, School of Medicine and \\ Dentistry', Rochester, Neze' York)
}

(Received for publication March 11, 1937)

The interesting clinical syndrome produced by tumors of the glomic structures in the extremities was first clescribed by Masson in 1924 (1) and called by him, glomus tumors. We have collected from the literature seventy-four cases of this condition (Table I). This condition is easily

TABLE I

Cases reported

\begin{tabular}{|c|c|c|c|c|c|}
\hline Author & $\begin{array}{c}\text { Year } \\
\text { re- } \\
\text { port- } \\
\text { ed }\end{array}$ & $\begin{array}{c}\text { No. } \\
\text { of } \\
\text { cases }\end{array}$ & Sex & Location & Duration \\
\hline Masson & 1924 & 3 & les & Subungual & 5 to $30 \mathrm{yrs}$. \\
\hline $\begin{array}{l}\text { Martin-Dechaume.... } \\
\text { Masson-Gery ....... }\end{array}$ & $\begin{array}{l}1925 \\
1927\end{array}$ & $\begin{array}{l}2 \\
4\end{array}$ & $\begin{array}{c}\text { Females } \\
3 \text { males }\end{array}$ & Subungual & - to $25 \mathrm{yrs}$. \\
\hline 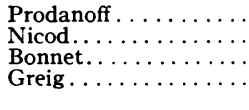 & $\begin{array}{l}1927 \\
1927 \\
1927 \\
1928\end{array}$ & $\begin{array}{l}1 \\
1 \\
1 \\
2\end{array}$ & $\begin{array}{l}\text { Male } \\
\text { Female } \\
\text { Female } \\
\text { Male } \\
\text { Female }\end{array}$ & \begin{tabular}{l|} 
Thigh \\
Subungual \\
Subungual \\
Arm \\
Calf
\end{tabular} & $\begin{aligned} 13 & \text { yrs. } \\
4 & \text { yrs. } \\
36 & \text { yrs. } \\
10 & \text { yrs. } \\
8 & \text { yrs. }\end{aligned}$ \\
\hline 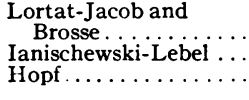 & $\begin{array}{l}1928 \\
1928 \\
1930\end{array}$ & $\begin{array}{l}1 \\
1 \\
4\end{array}$ & \begin{tabular}{|l|} 
Female \\
Female \\
2 males \\
2 females
\end{tabular} & $\begin{array}{l}\text { Subungual } \\
\text { Finger }\end{array}$ & $\begin{array}{l}16 \text { yrs. } \\
18 \text { yrs. } \\
4 \text { to } 16 \text { yrs. }\end{array}$ \\
\hline $\begin{array}{l}\text { Picard.. } \\
\text { Dupont . }\end{array}$ & $\begin{array}{l}1931 \\
1931\end{array}$ & $\begin{array}{l}1 \\
2\end{array}$ & $\begin{array}{l}\text { Male } \\
1 \text { female }\end{array}$ & Subungual & Long time \\
\hline $\begin{array}{l}\text { Fernãndez and } \\
\quad \text { Monserrat.......... } \\
\text { Cascos-Costen ....... } \\
\text { Paulian, Popescu, }\end{array}$ & $\begin{array}{l}1931 \\
1932\end{array}$ & $\begin{array}{l}1 \\
1\end{array}$ & $\begin{array}{l}\text { Male } \\
\text { Female }\end{array}$ & Arm & $10 \overline{\mathrm{yrs}}$ \\
\hline $\begin{array}{l}\text { Marinesco-Slatina.. } \\
\text { Adair.................... }\end{array}$ & $\begin{array}{l}1933 \\
1934\end{array}$ & $\begin{array}{r}1 \\
10\end{array}$ & \begin{tabular}{|l} 
Female \\
4 females \\
6 males
\end{tabular} & $\begin{array}{l}\text { Rt. arm } \\
4 \text { subung. }\end{array}$ & $\begin{array}{l}\text { Long time } \\
\text { Av. } 9 \text { yrs. }\end{array}$ \\
\hline $\begin{array}{l}\text { Mason-Weil . . . . . } \\
\text { Oughterson } \ldots \ldots \ldots \ldots \\
\text { Stout } \ldots \ldots \ldots \ldots \ldots\end{array}$ & $\begin{array}{l}1934 \\
1934 \\
1935\end{array}$ & $\begin{array}{r}1 \\
1 \\
11\end{array}$ & $\frac{\text { Male }}{6 \text { females }}$ & $\begin{array}{l}\text { Lt. knee } \\
\text { Lt. thumb } \\
4 \text { subung. }\end{array}$ & $\begin{array}{l}37 \text { yrs. } \\
1 \text { to } \overline{30} \text { yrs. }\end{array}$ \\
\hline $\begin{array}{l}\text { Bailey . . . . . . . } \\
\text { Love...... } \\
\text { Lewis-Geschickter ... }\end{array}$ & $\begin{array}{l}1935 \\
1935 \\
1935\end{array}$ & $\begin{array}{r}7 \\
1 \\
17 \\
74\end{array}$ & \begin{tabular}{|l|}
5 males \\
Male \\
10 females \\
7 males \\
aases
\end{tabular} & $\begin{array}{l}\text { 2 subung. } \\
\text { Lt. elbow } \\
\text { Arms and } \\
\text { legs }\end{array}$ & $\begin{array}{l}4 \text { to } 20 \mathrm{yrs} . \\
- \text { to } \overrightarrow{15} \mathrm{yrs} .\end{array}$ \\
\hline
\end{tabular}

diagnosed by anyone conversant with the condition but, according to the experience of Lewis and Geschickter (22), the clinical diagnosis is frequently not made. The recent literature contains several excellent clinical and pathological studies of the condition $(3,4,5)$. We wish to add two typical cases with the characteristic symptomatology and histological appearance. Our purpose is not one to add to the limited number of cases so far reported in the literature but to re-emphasize the significance of the lesion and particularly to record studies in the derangement of the vasomotor mechanism which is one of the outstanding characteristics of the disease. The latter has been recognized, but its nature has not been carefully investigated previously.

The following two cases have been seen in this clinic.

\section{CASE REPORTS}

Case I, Number 95098, married, white female, aged 64 years, first seen in the surgical clinic on October 23, 1934. Chief complaint-Injury to the left thumb. Present illness-Caught left thumb in a door this morning. She has had a red spot on the volar surface of the thumb for twenty-five years. It is very sensitive to the slightest trauma and causes referred pain over the hand and up the arm. Physical examination-Negative findings except for the left thumb. There is no appreciable swelling but on the volar surface, distal phalanx of the left thumb, there is a small dark purplish-red area about $1 \mathrm{~cm}$. in diameter which is extremely sensitive to touch. There is some localized vasodilatation around this area associated with increase in surface temperature and local perspiration. A diagnosis of glomus tumor was made by Dr. Thornton. She was given $50 \mathrm{mgm}$. hours of radium unfiltered to this area, partly as a therapeutic test to verify the diagnosis of glomus tumor. She failed to respond as is the rule with this lesion, thus making the diagnosis of glomus tumor even more certain. On November 23, a local excision of the tumor was made under Evipal anesthesia. Prior to and after excision, temperature readings were made of both hands and forearm. Complete relief of excruciating pain which had been present on tactile stimulation for twenty-five years was obtained by simple excision locally of the intact tumor. Histological studies revealed the characteristic appearance of a glomus tumor.

Case II, Number 84682, married, white female, aged 23 years, seen in the surgical outpatient on January 18, 1935 , because of melena. During routine physical examination, a pea-sized purplish-red, extremely sensitive tumor was noted on the terminal phalanx of the second left digit. It was just under the base of the nail and on its inner aspect. She states that it is extremely sensitive to touch. She does not remember how long she has noticed this lesion, but feels sure it is at least fifteen years. She had consulted several physicians in years past regarding this pain but had given up hope of relief as the remedies suggested were ineffective. The bleeding per rectum was accounted for on the basis of internal hemorrhoids. On 
February 15, 1935, excision was performed under gasoxygen. Histological studies revealed the characteristic appearance of a glomus tumor.

The clinical pictures of these two cases are typical. The outstanding characteristic of the lesion is pain usually of a peculiarly excruciating quality produced by the lightest pressure. In both cases the patients had had the lesions for years and had consulted many doctors without obtaining relief. In the early years the pain was more localized to the site of the lesion or the digit involved but later the pain was projected farther up the ex-

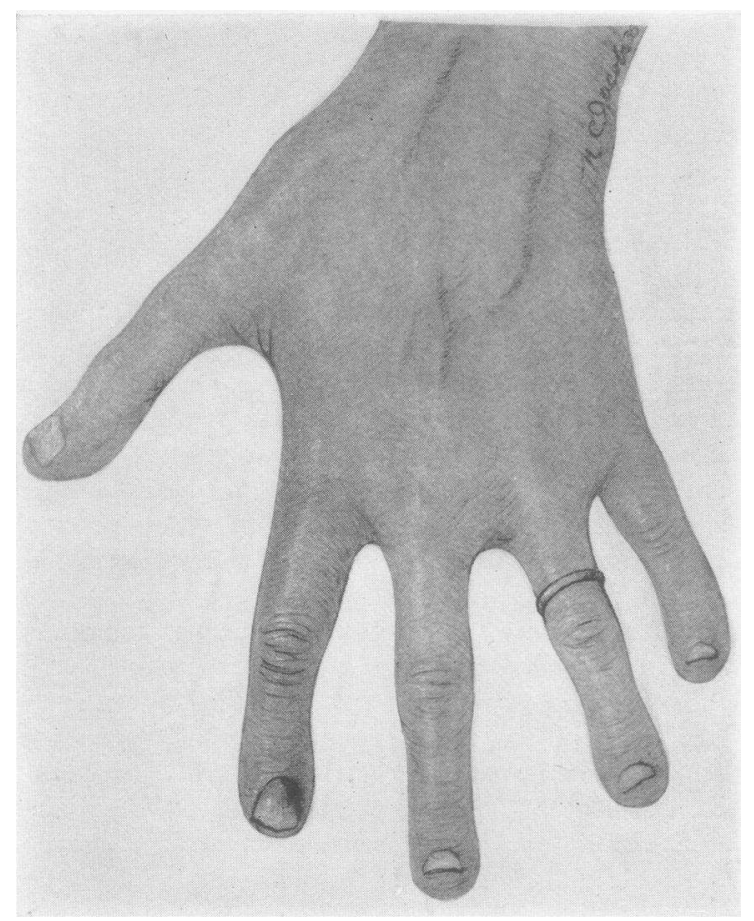

Fici. 1. Case 2, Showing the Discoloration of the

Tumor beneath the NaIl of the Index Finger

tremity as well. Both patients had noticed an increased warmth in the involved region. The lesions had the characteristic purplish coloration, they were from five to eight $\mathrm{mm}$. in diameter; in one case the tumor was on the volar surface of the distal phalanx of the thumb, the other one was under the nail of the left index finger near its base. In the latter case the thickness of the nail was definitely diminished over the lesion, its surface was bulged upward by the tumor and the purple discoloration could easily be seen through the nail (Figure 1).
Several authors in discussing the richness of nerve fibrils found in the glomus tumors have suggested their relationship to the pain on the one hand and the vasomotor system on the other, but no accurate studies of the vasomotor mechanism involved have as yet been recorded. We have knowledge of a number of pathological conditions which cause abnormal vasoconstriction but those which produce vasodilatation are less well known.

\section{OBSERVATIONS}

The following procedure was used in both cases in recording the vasomotor changes. The temperatures of several digits and of the forearms were taken at five minute intervals; all reaclings were recorded in the constant temperature room. After obtaining a base line in the initial readings, both hands were immersed in cold water at $15^{\circ} \mathrm{C}$. for five minutes. After quickly drying the hands without rubbing, the temperature readings were resumed and the rate at which the different points recovered from the cold was recorded. Similar observations were made at various times after operation.

The normal response following this standard cooling in water is a gradual reheating of the hand the speed of which varies somewhat in different individuals and according to the physiological condition of the individual but which is always synchronous on the two sides. In the presence of a glomus tumor, there was regularly an asymmetrical response. Frequently, the initial temperature level and the minimum temperature produced by cooling were higher on the involved side than on the opposite one. But whether or not this was true, a very rapid reheating of the hand was always observed on the affected side; within ten minutes there was a difference of six to eight clegrees between the affected hand and the uninvolved one. Also, it was noted that this evidence of vasodilatation was not limited to the affected digit nor to any peripheral nerve field but covered the entire hand. Thus in both cases the palmar surface of the fifth finger (ulnar nerve) responded in practically the same manner as the involved and contiguous digit (median nerve). After the removal of the glomus tumor, the abnormal vasodilatation eventually disappeared completely as measured by the response to this standard test and the two sides became symmetrical as 

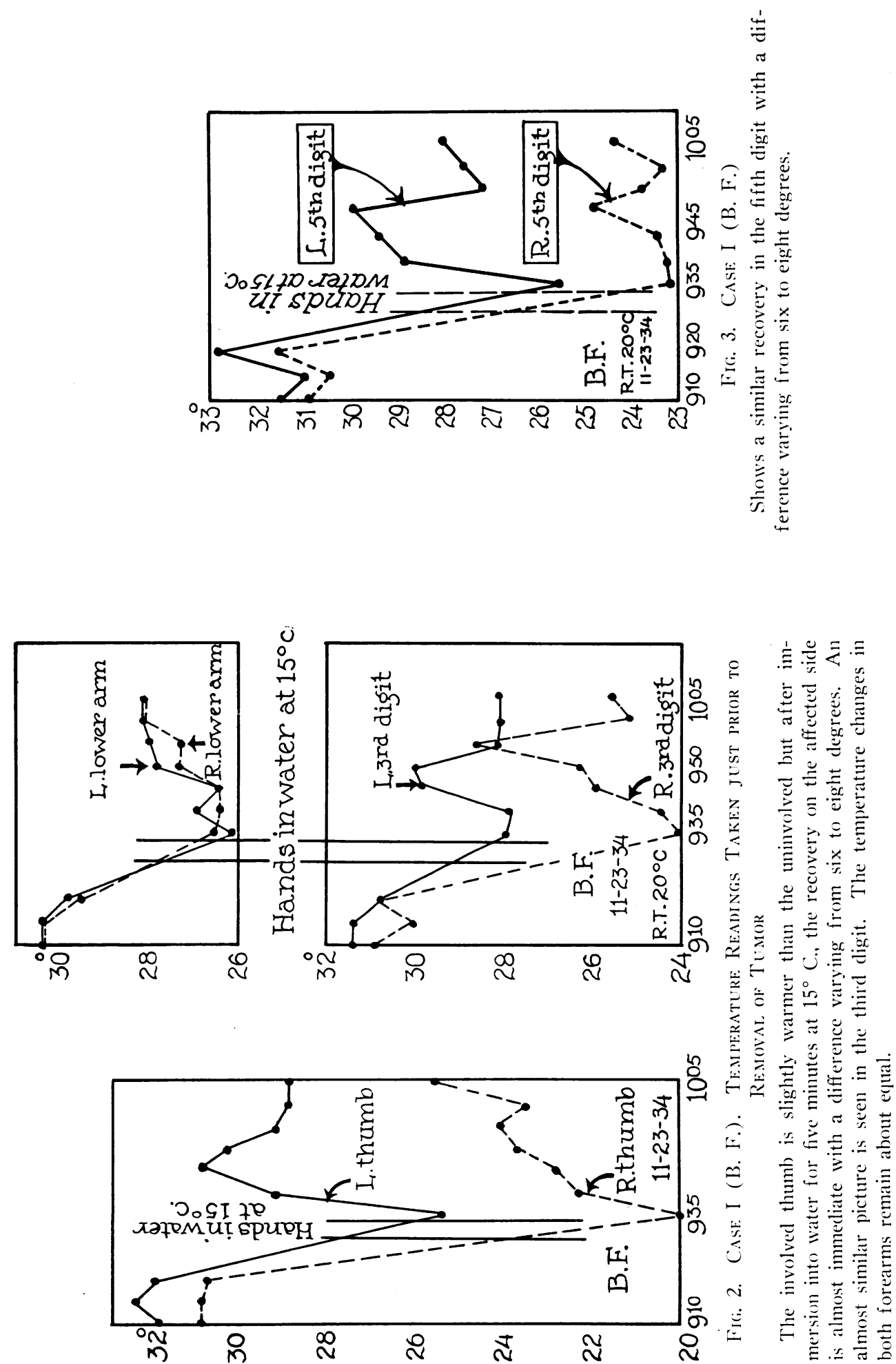

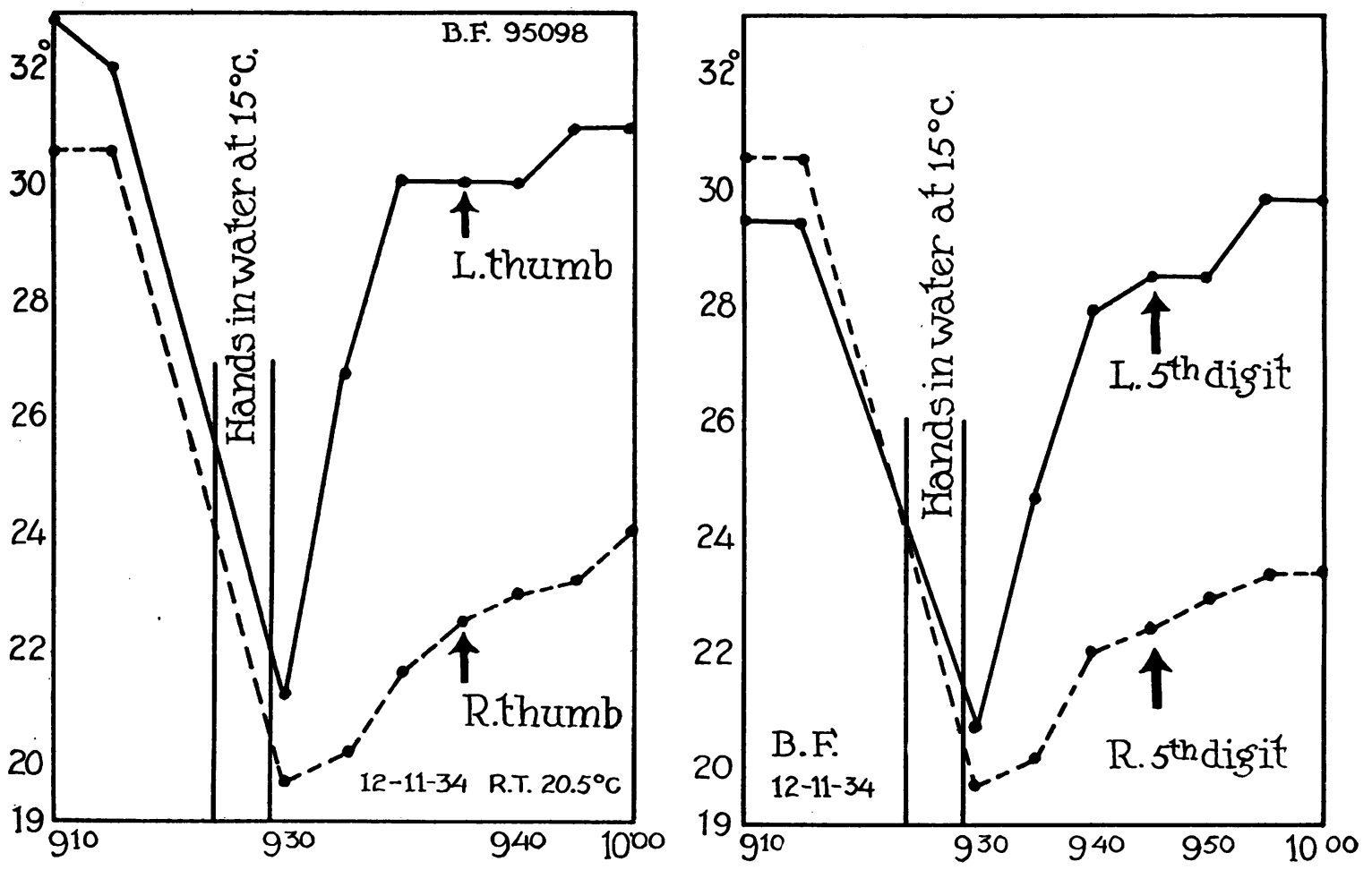

Fig. 4. Case I (B. F.). Temperature Readings Taken Three Weeks after Operation

The vasomotor disturbance is still present. At this time, the patient still had a dull ache over the scar and there was slight tenderness to pressure. These temperature changes lasted for about three months at which time all symptoms had completely disappeared.
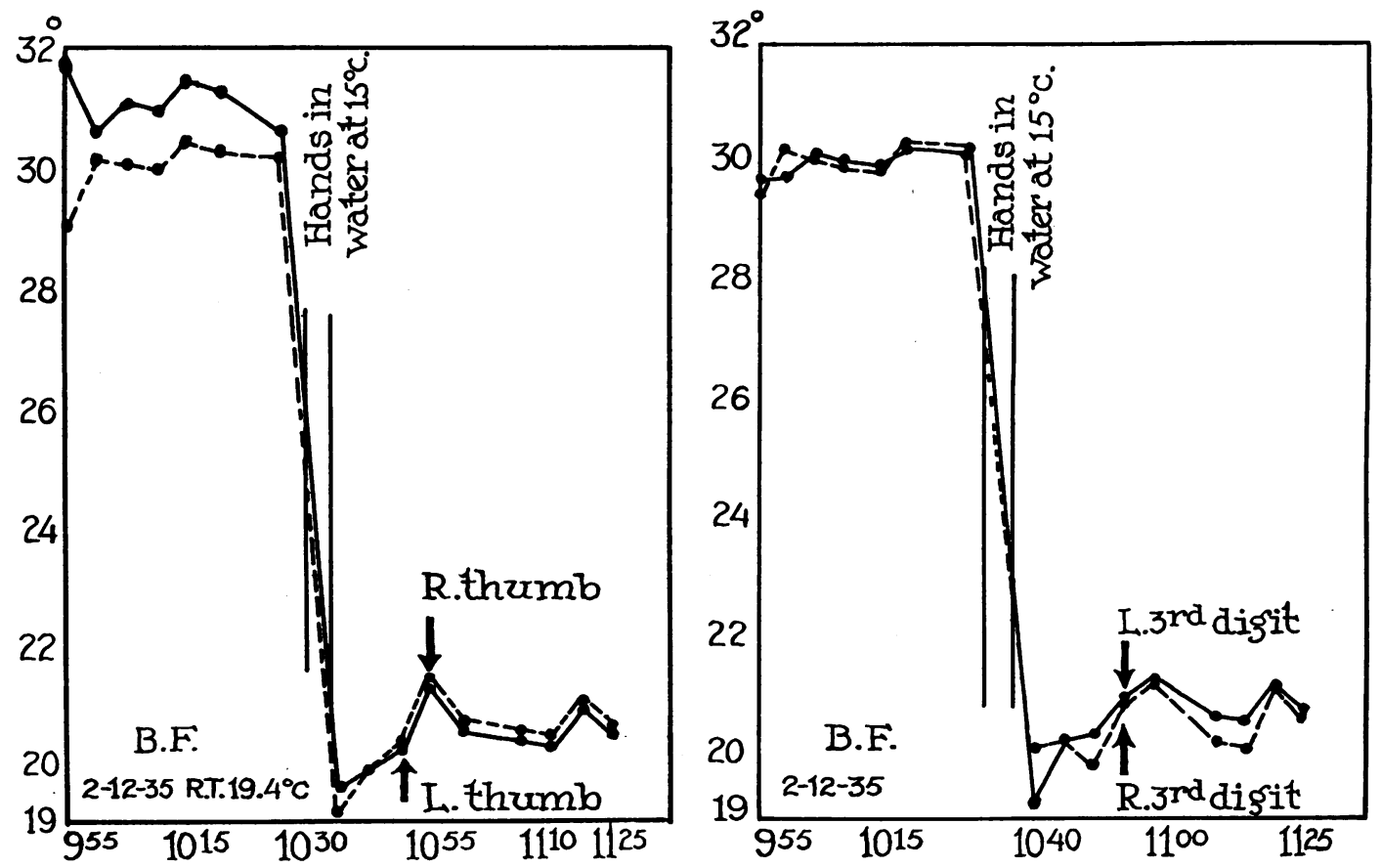

Fig. 5. Case I (B. F.). Temperature Changes Taken Three Months after Operation Showing a Uniform Recovery on Both Sides 

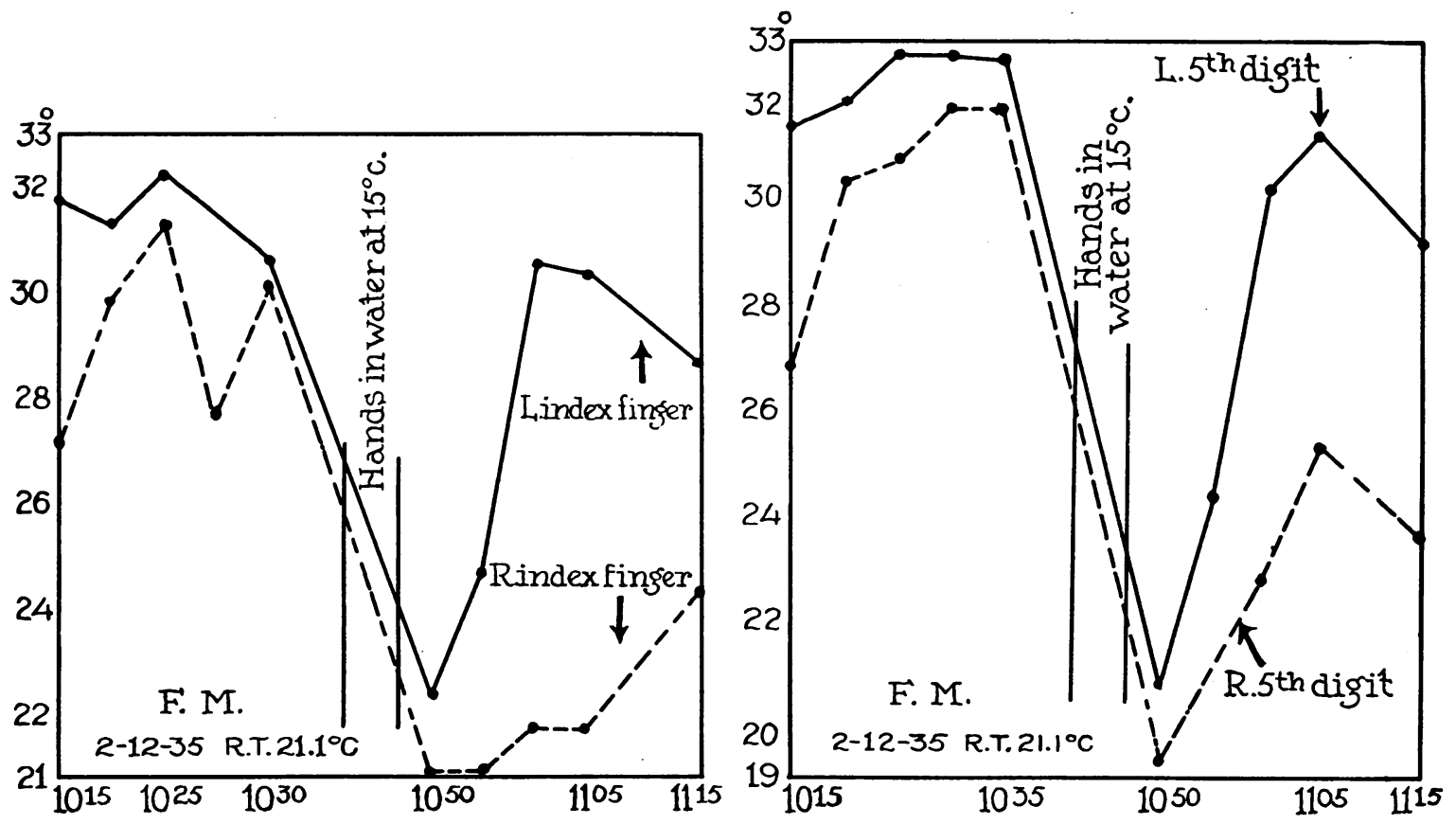

Fig. 6. Case II (F. M.). Temperature Readings Taken prior to Operation

The changes are similar to those recorded in Case I. The lesion is located on the left index finger but here again, the fifth digit presents the striking vasomotor changes.
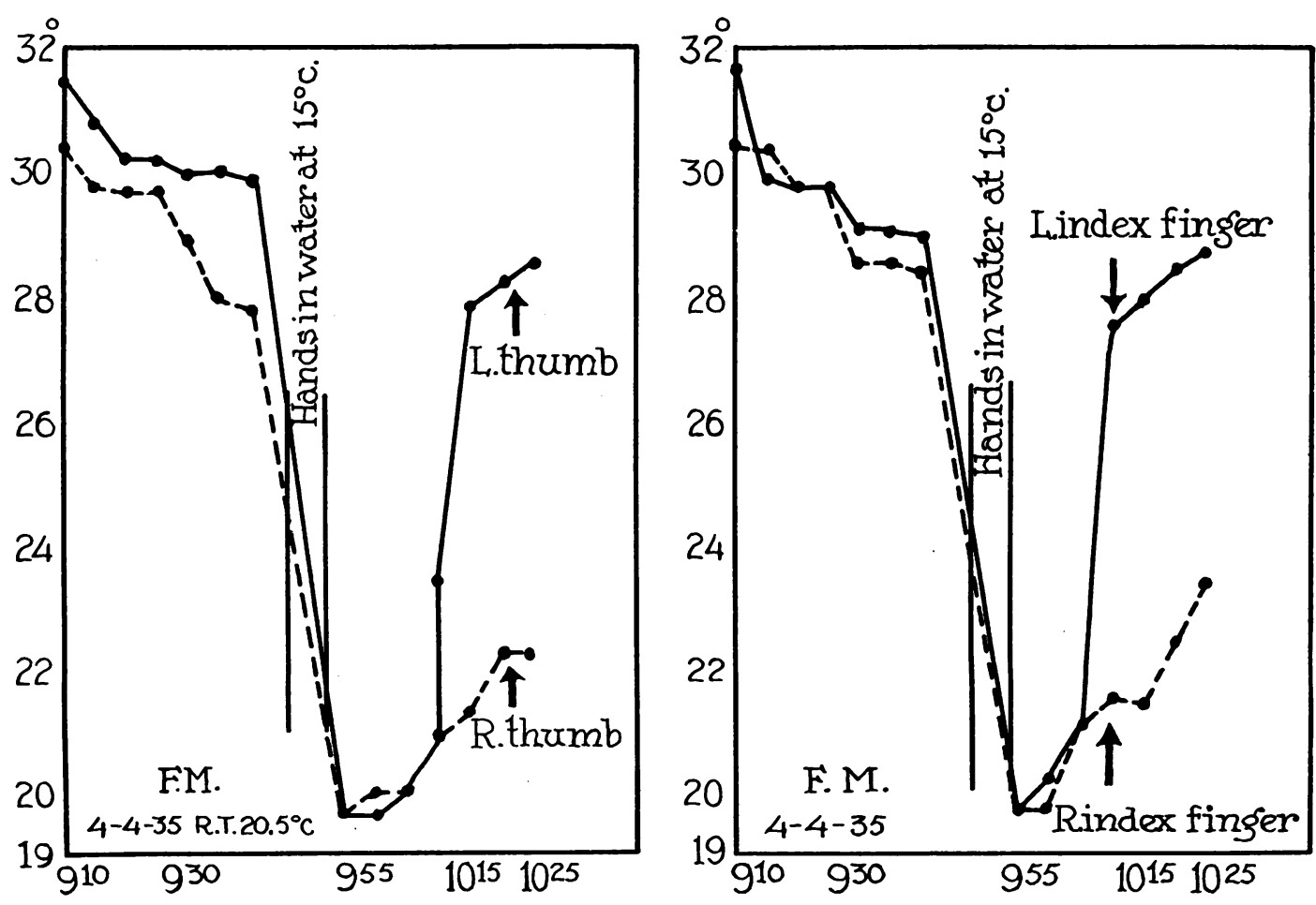

Fig. 7. CASE II (F. M.)

Almost two months after removal of the tumor, there is still evident the disturbance in the vasomotor mechanism. The patient still complained of a dull ache over the scar, and there was slight ten. derness to pressure. 
in the normal individual in their recovery from cooling. However, in each case a period of time elapsed before the temperature response returned to normal-in the first case this interval was short cold water, recovery to the previous temperature on the involved side is very rapid. These observations also suggest that this effect must be due to a reflex, the efferent arc of which is not
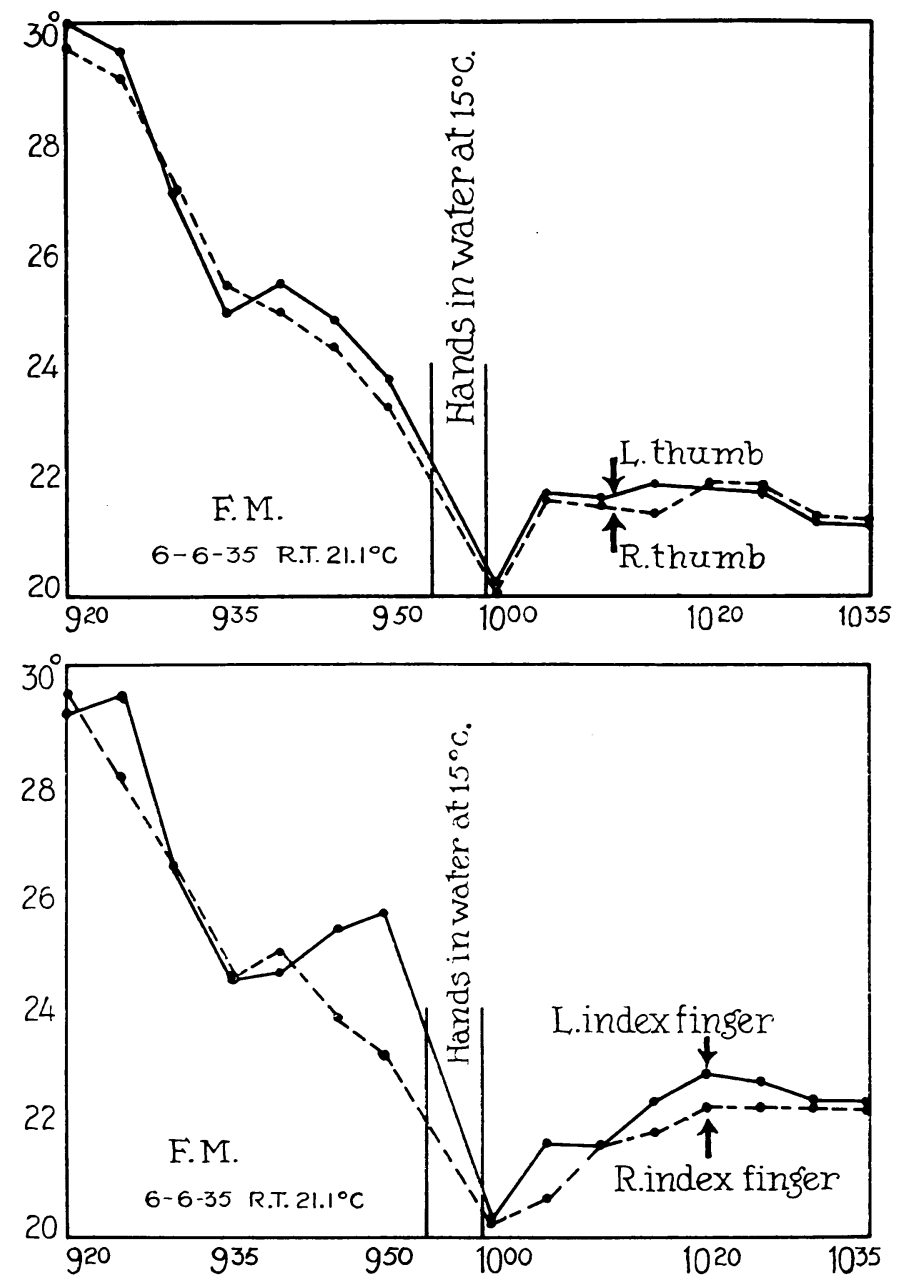

Fici. 8. CASE II (F. M.)

Four months after operation, there is a similar recovery to cold stimuli on the two sides and all symptoms have disappeared.

(about 3 to 4 weeks) but in the second case it lasted more than eight weeks. In both cases the continuation of the abnormal vasodilatation seemed definitely to be correlated with pain or sensitivity in the region of the scar (Figures 2 to 8 ).

\section{DISCLSSION}

The clata from these two cases indicate the extent of the vasodilatation accompanying glomus tumors in the extremities. After immersion in limited to the peripheral nerve field in which the sensory stimuli arise. Probably this means that the reflex arc extends back at least to the spinal cord although we cannot eliminate the theoretical possibility of the reflex occurring at the level of the sympathetic ganglia.

The persistence of a considerable vasodilatation as shown by our studies for as long as eight weeks after operation also throws some light on the character of the sensory stimulus. The vasodilatation seemed to be related with the per- 


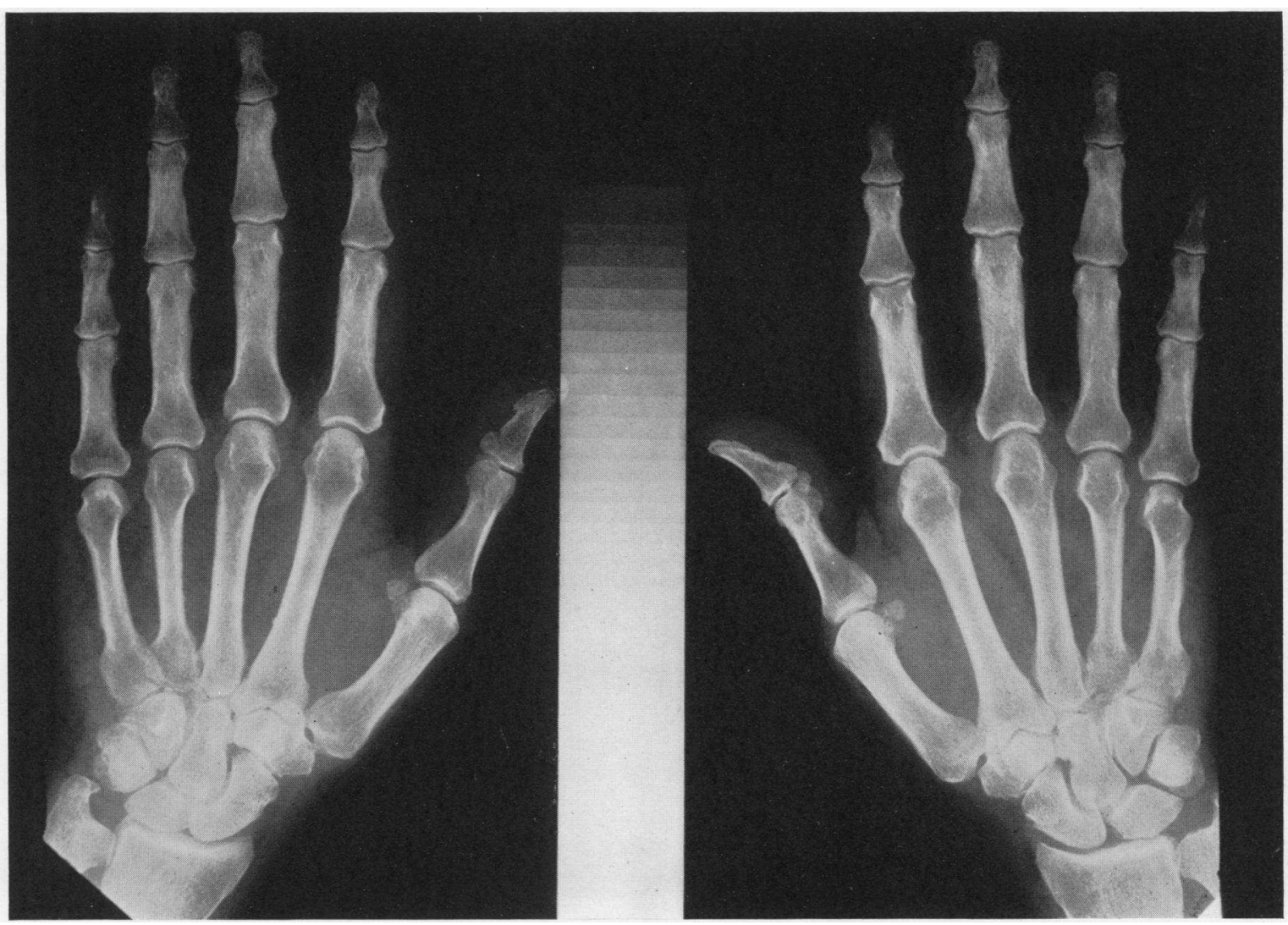

Fig. 9. Photograph of Case. I

There is noted a slight decrease in the density of the distal phalanx on the affected side but there is no true osteoporosis.

sistence of some discomfort in the region of the previously excised tumor. In the first case where the tumor was comparatively small and superficial, the tenderness of the scar lasted but a brief time. In the second case where the tumor extended from just under the nail around the phalanx into the pulp of the finger tip, sensitiveness of the scar and some spontaneous discomfort continued for two months and the abnormal vasodilatation persisted coincidently. These facts suggest that the vasodilatation of the tumor is related causally to the extremely painful sensory stimulation. If this is the case, it is dissimilar to the more common effect of painful stimuli which usually cause vasoconstriction rather than vasodilatation in the extremities. A possible relationship is also suggested between the mechanism involved in glomus tumor and the painful vasodilatation of erythromelalgia.

In connection with the vasomotor changes as- sociated with glomus tumors, we were also interested, from the theoretical point of view, in studying the character of the bone in these digits. Leriche (23) maintains that vasodilatation in bo:e is the mechanism by which osteoporosis is produced in the interesting clinical syndrome known variously as reflex traumatic arthritis or painful reflex osteoporosis. In our cases, no such osteoporosis was found in spite of persistent vasodilatation for many years. The slight difference in the density of the phalanges on the involved and uninvolved side, might be easily accounted for by the atrophy of clisuse arising from the attempt to protect the involved hand. In the second case where the glomus tumor extended down from a subungual position to the ventral surface of the finger, it also caused a distortion of the shaft of the phalanx in the immediate vicinity of the tumor, obviously due to local pressure. In neither instance was there any marked diffuse decrease in bone density nor 


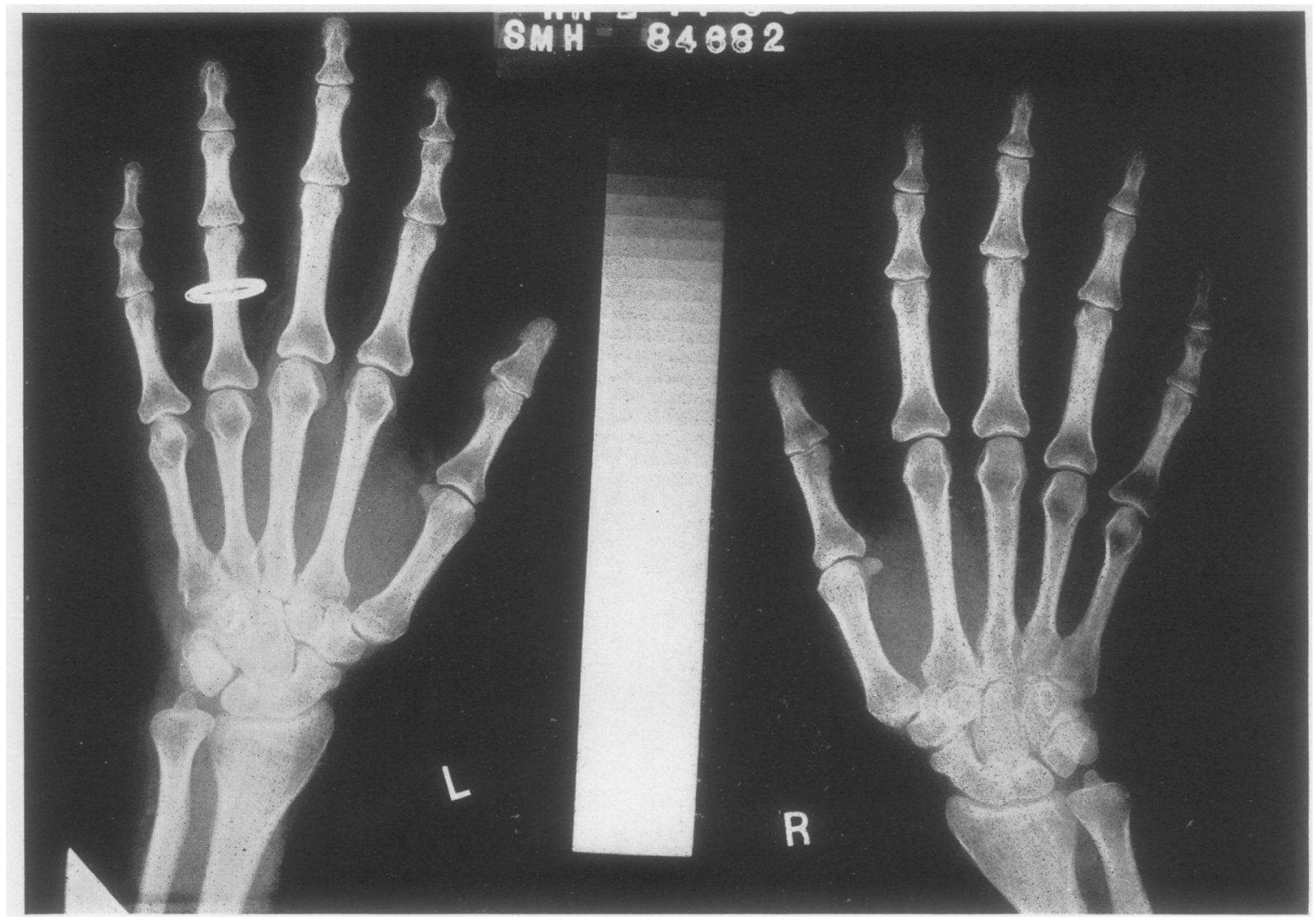

Fig. 10. Photograph of Case II

There is noted some thinning out of the shaft on the left index finger due to local pressure but no generalized changes that usually accompanies painful osteoporosis.

any tendency towards a spotty osteoporosis such as characterize reflex traumatic arthritis. This same observation that persistent dermal vasodilatation fails to produce osteoporosis has also been made in erythromelalgia by one of the authors with Dr. J. J. Morton. These considerations indicate either a dissociation of vasodilatation in the skin and in the underlying bone, or that vasodilatation is not a sufficient cause in and of itself to produce osteoporosis (Figures 9 and 10).

\section{CONCLUSIONS}

1. Two typical cases of glomus tumor are added to those already collected, and the importance of diagnosing this condition is reemphasized.

2. Studies of the vasomotor mechanism involved are recorded. The efferent side of the reflex is not limited to the peripheral nerve distribution of origin. The vasodilatation associated with the tumors completely disappears after surgical removal.

3. The persistence of the vasodilatation for two to three months associated with discomfort in the scar suggests that pain acts as the afferent stimulus which produces the characteristic vasodilatation.

\section{BIBLIOGRAPHY}

1. Masson, P., Le Glomus Neuromyo-arteriel des regions tactiles et ses tumeurs. Lyon chir., 1924, 21, 257.

2. Martin, J. F., and Dechaume, J., Les Tumeurs Glomiques. Ann. d'anat. path., 1925, 2, 239.

3. Masscn, P., and Gery, L., Les Tumeurs Glomiques sous-cutanées en dehors des doigts. Ann. d'anat. path., 1927, 4, 153.

4. Prodanoff, A., Sur I.a localisation des tumeurs glomiques. Ann. d'anat. path., 1927, 4, 147.

5. Nicod, J. L., Le (ilomus neuromyo-artériel. Souscutané et ses tumeurs. Schweiz. med. Wchnschr., 1927, 57, 1177.

6. Bonnet, P., Tumeur sous-ungueale doulouresse. Lyon chir., 1927, 24, 718. 
7. Greig, D. M., Subcutaneous glomal tumours; painful subcutaneous nodule. Edinburgh M. J., 1928, 35, 565.

8. Lortat-Jacob, L., and Brosse, T., Tumeur sousunguéale violacée et douloureuse avec causalgie du membre supérieur. Bull. Soc. franc. de dermat. et syph., 1928, 35, 305.

9. Ianichewski, A., and Lebel, M., Une variété de Neuralgie. La sympathalgie due a une tumeur glomique. Presse méd., 1928, 36, 116.

10. Hopf, M., Uber Tumoren des neuromyoarteriellen Glomus (Masson). Frankfurt Ztschr. f. Path., 1930, 40, 387.

11. Picard, H., Utber seltene Tumoren am Nagelbett. Zentralbl. f. Chir., 1931, 58, 2133.

12. Dupont, A., Aspects Atypiques des Tumeurs Glomiques. Rev. belge. sc. méd., 1931, 3, 624 .

13. Fernández, A. A., and Monserrat, J. L. E., Nódulos doloros de la oreja. Semana méd., 1931, 2, 1693.

14. Cascos, Alvarez and Costen, Clinical and histopathological study on the so-called subungual glomal tumors. Arch. españ. oncol., 1932, 2, 391.

15. Paulian, D. E., Popescu, S., and Marinesco-Slatina,
D., Tumeur Glomique sous-unguéale suivie d'hemihyperthermie et guérison complète après l'ablation Chirurgicale. Ann. d'anat. path., 1933, 10, 271.

16. Adair, F., Glomus tumors. Am. J. Surg., 1934, $25,1$.

17. Mason, M. L., and Weil, A., Tumor of a subcutaneous glomus. Surg., Gynec. and Obst., 1934, 58, 807.

18. Oughterson, A. W., Presentation of a case of subungual glomus tumor of the left thumb. The Soc. of Clin. Surg., 1934, 4.

19. Stout, A. P., Tumors of the neuromyo-arterial glomus. Am. J. Cancer, 1935, 24, 255.

20. Bailey, O. T., The cutaneous glomus and its tumorsglomangiomas. Am. J. Path., 1935, 11, 915.

21. Love, J. G., Tumor of a subcutaneous glomus or tumor of the neuromyo-arterial glomus. Report of a case. Proc. Staff Meet., Mayo Clin., 1935, 10, 593.

22. Lewis, D., and Geschickter, C. F., Glomus tumors (arterial angioneuromyoma of Masson). J. A. M. A., 1935, 105, 775.

23. Leriche, R., and Fontaine, R., Chirurgie du Sympathique. Rev. Neurol., 1929, 1, 1046. 